\title{
"LA JUSTICIA CON TOGA" DE RONALD DWORKIN: ¿LOS JUECES SON FILÓSOFOS O SON INTÉRPRETES MODERADOS?
}

\author{
JUSTICE WITH A TOGA BY RONALD DWORKIN: \\ Are judges Philosophers? or just moderate interpreters?
}

\section{Carlos Alberto Agudelo Agudelo*}

Agudelo A. Carlos A. Sophia N 7 - 2011. ISSN: 194-8932 Págs. 29-144.

Recepción: Junio 26 de 2011

Aceptación: Agosto 3 de 2011

"Sólo somos abogados, no filósofos. El derecho tiene su propia disciplina, su arte específico. Cuando vas a la facultad de derecho te enseñan lo que es pensar como un jurista, no como un filósofo. Los juristas no intentan decir grandes cuestiones conceptuales de la teoría ética o política. Deciden cuestiones concretas al por menor, una por una, de una forma más limitada y circunscrita. Sus herramientas de argumentación no son aquellas imponentes que se encuentran en los tratados de filosofía, sino los más caseros y confiables métodos del análisis textual detallado y la analogía" (DWORKIN, 2007: 78-79)

RESUMEN

Este texto señala el debate sobre el concepto de derecho en la obra "La justicia con toga". En segundo lugar, se presenta la idea general del debate que Dworkin tiene con el pragmatismo. En el tercer punto, está la incertidumbre de Dworkin acerca de la contribución de las teorías del derecho en las cortes. La cuarta parte, presenta la moral de Dworkin para defender sus tesis y finiquitar la polémica con los poshartianos. Finalmente, se exponen las ideas acerca de la interpretación resultado de la práctica judicial.

\section{PALABRAS CLAVE}

Dworkin, filósofos del derecho, Hart, interpretación, Justicia con toga, moral, práctica judicial y pragmatismo.

ABSTRACT

This document outlines the debate on the concept of Law in the work "Justice with a Toga". Secondly, a general idea on Dworkin's debate of pragmatism is presented. Thirdly there is Dworkin's uncertainty about the contribution of Law theories

\footnotetext{
Candidato a Doctor en Derecho, Maestría en Filosofía, Licenciado en Filosofía y Letras, Docente Universidad de los Andes, integrante Grupo de Investigación Estudios jurídicos y socio jurídicos Universidad de los Andes. agudelo972@uniandes.edu.co Carrera 1 No. 18A-12 Bogotá, Colombia.
} 
in court. The fourth part presents Dworkin's moral to defend his thesis ending with the post hartian discussion, and finally some ideas on the judicial practice interpretation of results are exposed.

\section{KEY WORDS}

Dworkin, philosophers of law, Hart interpretation, justice robe, moral, judicial practice and pragmatism.

\section{INTRODUCCIÓN}

La anécdota con la que inicia Dworkin su última obra, La justicia con toga (Dworkin, 2007), cuando cita a Holmes sobre la respuesta que este último da a Hand a la pregunta, de si los jueces están o no para hacer justicia, es bastante persuasiva en los trabajos de teoría jurídica. Holmes, le responde a Hand con un rotundo no: los jueces no están para hacer justicia. Este debate sobre la aplicación de la justicia ha sido el "cabo de hornos" en la filosofía del derecho. ¿Están los jueces destinados a realizar o buscar la justicia, o simplemente su función es aplicar la norma? Si es esto último, la norma jurídica nada tiene que ver con la justicia, pero si es lo contrario, las normas jurídicas deben incorporar la justicia, de modo que el juez debe corregir en sus fallos las normas injustas. Ahora bien, para Dworkin la corrección de las normas injustas es un trabajo que deben hacer los jueces, no los teóricos del derecho.

El título de su obra, "La justicia con toga", no es más que una sugerencia a los teóricos del derecho y entre ellos, Herbert Hart y sus seguidores, para que, cuando se hable del derecho y la justicia, es mejor dejárselo a los jueces y no a los académicos. La cita del juez Holmes hecha por Dworkin, tiene un sentido muy importante durante todo el trabajo y con ella se enfrentarán los debates sobre el positivismo jurídico, el pragmatismo, el originalismo y los problemas sobre la vinculación o no de la moral al derecho. Dichos debates producirán otros como: ¿las proposiciones jurídicas representan hechos como las proposiciones filosóficas?, es decir, cuestiones que conducen hacia la naturaleza del derecho para indagar si su estructura está conformada por entidades sociales o entidades naturales. Esta es una discusión que se originó en el Círculo de Viena, donde se estableció un ataque fuerte a todo lenguaje metafísico o ininteligible, y donde se buscaba que el lenguaje fuera lo más claro posible. Se concluyó que las proposiciones representaban un lenguaje lógico-perfecto, mientras que el lenguaje moral, ético, jurídico, político, tienen una forma distinta de manifestarse y, por lo tanto, su claridad no es tan manifiesta, ya que no se mantiene una estructura esencial que se deje percibir con solidez. Estos diálogos se llevaron también al derecho, al decir de Dworkin:

"No debemos cometer el error de pensar que hay algún tipo de distinción natural entre entidades sociales que identifican las estructuras jurídicas, como sí estas de por sí tuvieran algún tipo de naturaleza esencial que se intenta recoger con tales distinciones.... Burocracia, meritocracia, matrimonio y derecho no son conceptos de clase natural cuya naturaleza esencial venga dada por su naturaleza física o biológica." (Dworkin, 2007: 13)

Ahora bien, no sólo es R. Dworkin, si no la teoría jurídica en general, la que se ha ocupado desde hace muchos años por cuestionar los diferentes conceptos del derecho que se han producido en las diferentes doctrinas. Pero fue con Herbert Hart con quien Dworkin estableció su más ferviente discusión académica (Hart, 2004) y, es por esta razón, que en La justicia con toga, no duda en examinar los casos concretos más importantes que se han dado en torno al derecho. Aquí básicamente interesa rastrear el "concepto criteriológico"1 del derecho que es donde cree Dworkin está sumergido Hart, para contrastarlo con un "concepto interpretativo" del derecho, aceptado por Dworkin en esta última obra. Estos asuntos orientarán otras disputas internas dentro de la teoría jurídica, por ejemplo, ¿le es dado al juez interpretar el derecho cuando es vago o ambiguo? y si es así, ¿cómo lo debe hacer? Los casos difíciles en el derecho van a ser un buen ejemplo para comprender el debate entre Dworkin y

1 El concepto criteriológico se entiende como aquel que tiene ciertas propiedades identificables y desde allí se puede inferir lógicamente el significado del concepto que se intenta definir. Para Dworkin, esto es un error, ya que el concepto de derecho posee un significado interpretativo que no se deja encerrar en una fórmula matemática. Para Dworkin, el significado de derecho depende más de interpretaciones judiciales, prácticas, hechos concretos etc, es decir, el concepto interpretativo del derecho es más flexible que el simple concepto criteriológico que defiende Hart. 
Hart, además con los poshartianos, especialmente, Coleman y Waluchow (Escudero, 2004)

Finalmente, con base en estas ideas, para Dworkin, la experiencia judicial significará un asunto importante para definir un concepto interpretativo de la justicia, por encima de muchos postulados de los filósofos del derecho, que consideran la justicia y el derecho un tema desligado de las prácticas judiciales. El interés en este trabajo es presentar las principales discusiones que expone Dworkin en esta última obra donde quiere cerrar el debate con Hart $^{2}$, y al mismo tiempo, se trata de explicar por qué sus críticas no son del todo terminantes con el positivismo moderado o inclusivo, dejando claro en el ambiente judicial y político, que los jueces son simplemente hombres mortales (no jueces Hércules) que intentan, a pesar de su falencia filosófica, fallar con antecedentes judiciales caseros que sus colegas van estableciendo. Esto no quiere decir que los jueces no deban pretender, cada vez más, parecerse a los jueces filósofos.

\section{ALGUNOS PROBLEMAS LINGÜÍSTICOS SOBRE EL CONCEPTO DE DERECHO EX- PUESTOS POR RONALD DWORKIN}

Dworkin quiere indagar, si las teorías del derecho más influyentes son atractivas para resolver casos difíciles ${ }^{3}$ en derecho, y si no lo son, cuál teoría del derecho puede ser suficiente para emprender esta tarea. Sin embargo, no es su única finalidad, su idea es también ponerle fin al positivismo moderado de Hart y al positivismo jurídico inclusivo poshartiano. Dworkin cree, que su propuesta en la década de los setenta, ya había superado dichos postulados del positivismo moderado e inclusivo, y que no tiene sentido pensar el derecho como estos lo habían señalado. No obstante, tales postulados aun

2 Se debe recordar que este debate inicio en los años setenta y ochenta y desde allí se han escrito innumerables obras sobre este debate, sin embargo, este artículo quiere exponer la última respuesta que da Dworkin tanto a Hart como a los poshartianos en La justicia con toga. El imperio de la justicia y los derechos en serio es una respuesta de Dworkin al Concepto de derecho de Hart de 1961, mientras que el Postscriptum de Hart es una obra posterior donde responde a las críticas de Dworkin La justicia con toga es una respuesta de este último digámoslo así, al Postscriptum, sobre esto, casi no se ha escrito nada.

3 Entiéndase por caso difícil aquel donde el juez no puede resolverlo con la simple ley. permanecen con fuerza en la teoría del derecho. Dworkin quiere con La justicia con toga, explicar que el derecho ha cambiado sustancialmente. Para Dworkin, el derecho exige otras estructuras de pensamiento mucho más sólidas para comprender todo el significado que nos ofrece el derecho como campo semántico complejo. Argumenta que la Constitución de un país como regla suprema exige de los legisladores, jueces y demás, personas dentro de una "democracia asociativa" (Dworkin, 2007: 174-183) ${ }^{4}$ que observen el derecho en un sentido más amplio al establecido antes por el positivismo en mención. Ya no es un sistema de reglas como lo pensara J. Austin (2002) o Kelsen (2006) y, posteriormente Hart (2004), ahora se trata de ver los sistemas jurídicos como sistemas de reglas y principios. El derecho no se puede reducir a un concepto criteriológico (ley=derecho), donde el derecho se reduzca a una norma fría y calculadora, además por algo muy sencillo, el derecho no es matemático y las leyes son simples guías que orientan a los jueces para que en un caso concreto puedan ajustar la norma de forma equitativa.

Expliquemos esto mejor. Para Dworkin, existen palabras que no necesitan interpretación, pero hay otras como el derecho, la democracia, la justicia que si lo requieren. Por ejemplo, sobre el concepto criteriológico dice:

"La gente comparte el concepto de soltería solo cuando saben que un soltero es un varón no casado, por ejemplo, y comparten el concepto de triángulo equilátero sólo cuando saben que tal triángulo tiene lados de idéntica longitud. La equilateralidad es un concepto preciso. La soltería es un concepto razonablemente preciso,

4 La "democracia asociativa" se entiende como aquel grupo de socios que respetan a los demás como asociados de una empresa a través de dos principios básicos: la igualdad de consideración que indica que debemos poner el máximo empeño en asegurar que nuestros representantes políticos actúen con igual consideración para todos, evitando que tengan preferencias con un grupo especial, esto no implica justificar la igualdad matemática sobre los votos. Una igualdad de consideración se protege mejor si "consagramos ciertos derechos individuales en una Constitución que deban ser interpretados por los jueces antes que por los representantes electos". En segundo lugar, el autogobierno. Consiste en la responsabilidad personal en la identificación del valor en sus propias vidas, porque las mayorías no pueden justificar todas sus posiciones políticas de manera coercitiva sobre los demás. 
aunque tiene cierta imprecisión: ¿un varón de 18 años que nunca se ha casado es un soltero?" (Dworkin, 2007: 19)

Y más adelante sobre el concepto de clase natural expresa:

\begin{abstract}
"Algunos expertos saben mucho sobre el ADN del tigre; otras muchas personas saben que los tigres tienen ADN y que este les hace ser lo que son; todavía más gente no ha oído hablar del ADN, pero a pesar de ello suponen que todos los tigres poseen la misma estructura biológica.....A pesar de lo anterior, todos comparten el concepto de ser tigre" (Dworkin, 2007: 20)
\end{abstract}

Así pues, hay conceptos que representan hechos, un viejo debate que ya desde Platón en el Crátilo (Platón, 2003) se había planteado cuando distinguía el lenguaje natural del convencional y que posteriormente lo retomó la filosofía analítica con Russell (1972), Wittgenstein (2005), Austin J. L. (1990), Searle (1995) y demás. En todos ellos es común que no hay mayor problema con la definición de montaña, de tigre, con las definiciones matemáticas y físicas, por el contrario, se encuentran muchas dificultades cuando se quiere llegar a un acuerdo con la definición de moral, de ética, de derecho, política etc., aquí necesitamos las prácticas sociales, la costumbre, el uso del lenguaje, la interpretación, los principios, los valores, para así aproximarse a definiciones que nos puedan llevar a acuerdos y decisiones razonables. Para Dworkin el concepto criteriológico o de clase natural no puede apoyar una buena definición de lo que sea el derecho, por esta razón, opta por un concepto interpretativo. Sobre los conceptos interpretativos dice: "La gente comparte el concepto de justicia a pesar de los profundos desacuerdos que existen, tanto sobre los criterios para identificar la injusticia como sobre qué instituciones son injustas". Puede también la gente equivocarse en otros puntos, al decir de Dworkin: "sobre si un mineral dorado es oro o sólo pirita, o sobre si una ballena es un pez. Pero identificar tales errores presupone que subyace una práctica convergente que vincula el concepto a alguna concreta clase natural" (Dworkin, 2007: 21)

Dworkin, entonces, va a tomar partida por que el derecho se comprenda por un concepto interpretativo y no por uno criteriológico a lo Hart $^{5}$. "Los conceptos interpretativos requieren que las personas también compartan una práctica.... en mi opinión el concepto doctrinal del derecho funciona como un concepto interpretativo, al menos en las comunidades políticas complejas" (Dworkin, 2007: 22)

Según Dworkin, este camino metodológico de ver el derecho como concepto interpretativo va a llevar a los jueces a tomar decisiones en casos complejos, no sólo con base en las normas, sino con base en decisiones políticas, pues habrá casos donde la ley no es suficiente, es vaga o genera vacíos, así, el juez tendrá que ponderar diferentes situaciones para buscar la respuesta más razonable. El juez tendrá que hacer uso de las reglas interpretativas del derecho de concebir la jurisprudencia y la ley como una novela ${ }^{6}$ donde cada juez escribe el capítulo siguiente sin perder la coherencia con sus antecedentes judiciales. (Dworkin, 2007: 29) ${ }^{7}$ Miremos que piensa Dworkin sobre este quehacer de los jueces.

"Para la mayoría estamos ante una restricción absoluta. Pero no es absolutamente absoluta: aceptan que en casos muy atípicos los jueces pueden tener la obligación moral de prescindir del derecho sí este es muy injusto o quizás también cuando es muy inadecuado, procediendo a usar su poder político para evitar la injusticia o una gran ineficiencia...no es una cuestión sobre como figura la moral en la identificación del derecho, sino una cuestión sobre cuándo, si es que alguna vez, la moral requiere a los jueces actuar con independencia o incluso en contradicción contra el derecho" (Dworkin, 2007: 29)

5 Aunque Dworkin cree que Hart maneja un concepto criteriológico del derecho, ya que cree que dicho concepto a través de la regla de reconocimiento dice todo el derecho sin apelar a los principios, se sostiene en este texto, que Dworkin sigue equivocado al no aceptar la vinculación de los principios a la teoría del derecho que reconociera Hart en el Postscriptum. Hart acepta, al mismo tiempo, que la regla de reconocimiento guarda un grado de incertidumbre y que no es tan clara como lo pensara Dworkin.

- La metáfora de la novela la utiliza Dworkin en el texto: Cómo el derecho se parece a la literatura. En: La decisión Judicial. El debate Hart- Dworkin. Traducción de Juan Manuel Pombo Abondano. Bogotá: Siglo de hombres editores, universidad de los Andes, 2002

7 Sin embargo, esta no es la discrecionalidad judicial defendida por Hart en el Concepto del derecho, porque esta sólo se funda sobre la vaguedad del lenguaje jurídico, y al no aceptar los principios dentro de su teoría, dice Dworkin, tal discrecionalidad no debe aceptarse, ya que los principios que Dworkin agrega a su teoría, solucionan el problema. 
Este poder político está justificado en los principios que el derecho vaya aceptando o en los fines que el derecho puede ofrecer. Los principios del derecho desde Alexander Bickel en The Least Dangerous Branch: The Supreme Court at the bar of politics en 1962, la propuesta de F. Gény en la libre investigación científica, la tesis de Philipp Heck en la Jurisprudencia de intereses (Heck, 1932: 524) y que luego Robert Alexy con sus argumentos sistemáticos en su obra la Teoría de los derechos fundamentales (Alexy, 2007), subordinada a una Teoría de la argumentación jurídica (Alexy, 2007), son argumentos que promovieron el neoconstitucionalismo local, donde los jueces cumplen un papel relevante en la creación del derecho. En este orden de ideas, la moral tendrá una función central para enfrentar todas aquellas tesis que separan la moral del derecho. "Dentro de esta nueva estructura la moral desempeña un papel en dos lugares de la teoría jurídica: en el nivel iusfilosófico, cuando se atribuye valor a la práctica jurídica, y en el nivel de la aplicación judicial, cuando los jueces son instados a hacer justicia" (Dworkin, 2007: 31)

En definitiva, el concepto criteriológico del derecho de Hart es muy pobre para entender el campo semántico que comprende el derecho hoy en día, mientras que el concepto interpretativo de Dworkin es más razonable para abarcar las necesidades sociales, políticas, jurídicas y morales que enfrentan las sociedades contemporáneas.

\section{DWORKIN Y EL PRAGMATISMO}

Otro punto interesante que encontramos de la lectura de Dworkin es el pragmatismo. Las tesis pragmatistas dentro de su evaluación también serán atractivas, no para tomar partido por ellas, sino para revaluar sus argumentos entre ellos los de Richard Rorty (2000), aunque Dworkin aquí no tiene mucho éxito. En Dworkin vemos un pragmatismo más mesurado que el propuesto por los clásicos (James y Dewey), pues mientras estos tienen sus miras puestas en la utilidad, en lo mejor, en el futuro de una comunidad, en lo más deseable, etc., Dworkin, pretende todo esto, pero sin abandonar la ley y el precedente, situaciones estas que un pragmatista serio, como Rorty, mandaría al carajo. Dworkin piensa: "Los jueces deben de forma global obedecer al legislador y honrar las decisiones judiciales anteriores porque la capacidad del parlamento y de las instituciones judiciales para coordinar el comportamiento futuro es de gran utilidad para conseguir la eficiencia o cualquier otra finalidad, y esa capacidad se vería mermada si los jueces característicamente ignoran los pronunciamientos anteriores en sus nuevas decisiones" (Dworkin, 2007:32) Y páginas adelante, "desde hace décadas estos supuestos han sido desafiados por algunos juristas académicos que se autodenominan realistas jurídicos y que insisten que las proposiciones jurídicas no son ni verdaderas ni falsas, sino solo expresión de las preferencias subjetivas de los jueces o de otras autoridades, de modo que el intento de buscar los valores de verdad para las proposiciones jurídicas constituye una absurda pérdida de tiempo" (Dworkin, 2007:33)

En este orden de ideas, Dworkin quiere hacerle frente a un pragmatismo muy fuerte como el de Richard Rorty. Frente a él piensa que su lenguaje último 8 no es un argumento para sobrevalorar la realidad, y que el hecho de que nuestro lenguaje cambie, eso en nada cambiaría la realidad.

"Rorty dice que debemos abandonar la idea de que la indagación jurídica, moral e incluso la científica sean intentos de descubrir qué es lo que realmente hay, qué es realmente el derecho, qué quieren decir realmente los textos, qué instituciones son realmente justas o cómo es realmente el universo. Debemos abandonar la idea de que un vocabulario de conceptos, un conjunto de proposiciones, pueda ser más fiel que otro a una realidad que existe con independencia de ambos. En lugar de ello, debemos aceptar que el vocabulario que tenemos es sólo el que tenemos, el que parece irnos bien o sernos útil" (Dworkin, 2007:48)

Sin embargo, a pesar de lo que dice el profesor Dworkin, lo que desea Rorty no es cambiar la realidad, sino nuestra forma de comprender el mundo. Rorty no niega la realidad, lo que niega es como se predica la objetividad de la realidad, y este es otro asunto. Para Rorty existe la realidad, pero existen diferentes intenciones y preferencias de los hablantes a la hora de comprender y comportarse en la realidad. Ahora bien, si este asunto

$8 \quad$ Lenguaje último según Rorty, es aquel que estamos revisando constantemente, es una lucha con nuestras propias formas lingüísticas de ver y pensar el mundo, sin dejarse atrapar por reglas dogmáticas. 
se traslada al derecho, Rorty no va a defender las normas o leyes a capa y espada para entender el derecho, como si aquellas fueran una base sólida, es decir, un derecho basado en una definición matemática o criteriológica, pues esto no es afín al pragmatismo rortiano donde todo es revisable. Para Rorty, las normas pueden modificarse, porque están construidas a partir del lenguaje, un lenguaje que es modificable y no fundacionalista como lo pretende hacer ver Dworkin, cuando dice que el juez debe adjudicar el derecho establecido. Para Rorty el lenguaje permite el cambio constante de las definiciones de moral, de justicia, de derecho, democracia etc., ya que no hay allí nada firme. Sin embargo, para Dworkin la seguridad jurídica se apoya en leyes preestablecidas y no puede variar dependiendo de los lenguajes últimos de las personas, así que la propuesta de Rorty es demasiado peligrosa para el derecho. En últimas, lo que piensa Dworkin de Rorty, es que éste piensa cambiar la realidad a través del lenguaje, y aunque esto puede funcionar para la filosofía o la ciencia, para el derecho, es totalmente un fracaso. (Rorty, 2000:139).

Se explica esto mejor con un ejemplo:

"Es totalmente cierto que la altura del Everest no depende de las intenciones de los seres humanos, de la historia o de la cultura, aunque la métrica usada para describir su altura y el hecho de que nos importe saber cuánto mide dependen ciertamente de las intenciones y de la cultura. Así pues el pragmatista tendría que proporcionar significados especiales a frases tales como "independiente de la intención" para intentar explicar porque cuando el filósofo afirma que la realidad es independiente de la intención dice algo distinto de aquello que quiere decir la gente corriente cuando utiliza la misma frase" (Dworkin, 2007:51)

Dworkin está discutiendo con una corriente en filosofía (Rorty), que no niega la realidad, sino la forma como se comprende la realidad por medio del lenguaje. Según la filosofía analítica, por ejemplo, entre más claro sea el lenguaje mejor se comprende el mundo, y entre más abstracto sea la comunicación, más difícil se vuelve la comprensión del entorno. Por colocar un ejemplo, es más fácil comprender el derecho por medio de reglas claras que por medio de principios abstractos y variables, y en ese orden de ideas, es más atractivo para
Dworkin la tesis de Hart que la de Rorty, pues la formación en filosofía analítica que poseía Hart e influenciado por el primer Wittgenstein (donde se pensaba que el lenguaje es lógico-perfecto, es decir, el lenguaje tenía que ser una foto de la realidad y las proposiciones tenían que representar los hechos), lo hace más claro para establecer un concepto criteriológico del derecho ${ }^{9}$.

En el segundo Wittgenstein, el filósofo se retracta de lo que había dicho en el Tractatus lógico filosófico (Wittgensteini, 2005) diciendo que no hay un lenguaje perfecto para todo y que el lenguaje ético y moral, por ejemplo, dependerá del uso del lenguaje, o lo que es lo mismo, de la pragmática del lenguaje. Estas tesis las defiende, posteriormente, en las investigaciones filosóficas, influencia esta que se encuentra en el "segundo Hart" expuesto en el Postscriptum (Hart, 1994, 2002), donde apela a los principios para entender mejor el concepto de derecho, ya que no cree que el derecho tenga una forma matemática, sino que comprende formas complejas para encajar en la realidad. Pero Dworkin en La justicia con toga sigue sosteniendo que Hart mantiene la separación entre derecho y moral, y que por esta razón, sigue desconociendo la relevancia de los principios dentro de su teoría; con todo ello, queda la sensación de que Dworkin continua manteniendo sus críticas de los setenta y ochenta en Los derechos en serio y El imperio de la justicia, sin ceder nada a las correcciones que Hart hiciera en la última obra del Postscriptum.

"Los juristas a menudo se devanan los sesos y no se ponen de acuerdo respecto de a qué es lo que el derecho rectamente entendido exige en una determinada situación porque, aunque comparten la idea de que el derecho tiene algún

9 En Searle (1995) estaba muy claro que existen hechos brutos que expresan la realidad, pero existe otra realidad social que no está dada por hechos brutos, está dada por el lenguaje construido por las convenciones dentro de las prácticas sociales. El derecho por su parte no hace parte de esa realidad bruta, sino del lenguaje y este es el que debemos discutir. De ahí que ni los ataques a Rorty ni los ataques a Hart prosperen, porque estos están situados en el nivel lingüístico, mientras aquel (Dworkin) está situado en la realidad judicial, esto es, lo que hacen verdaderamente los jueces; según Dworkin, estos no se devanan los sesos diciendo que teoría es mejor que otra para fallar, sino como imperan los casos concretos dentro de un fallo. 
objetivo tienen explicaciones distintas, rivales y controvertidas acerca de cuál es tal sentido, bien de modo general, bien respecto a concretas áreas o doctrinas o reglas jurídicas" (Dworkin, 2007: 60) Así las cosas, para ir precisando más el asunto, Dworkin intenta desterrar del todo el pragmatismo de Rorty y el positivismo que Hart y sus seguidores quieren mantener; su metodología será un ataque a los filósofos del derecho que no poseen ninguna experiencia en la práctica judicial, mostrando esto como una debilidad de sus teorías. ${ }^{10}$

\section{LOS JUECES NO SON FILÓSOFOS: ¿TEORÍAS DEL DERECHO O PRÁCTICA JUDICIAL?}

Para Dworkin la respuesta favorable o no sobre una teoría del derecho dependerá de la solución que pueda presentar a los casos concretos, pero más aun, a los casos difíciles. La idea es saber cuál teoría del derecho sería más razonable para decidir dichos casos. Sin embargo, no se debe olvidar que para los "casos fáciles"11 las teorías no son importantes, para ello está la ley. Pero, para casos difíciles, las teorías positivistas pueden dar una respuesta, las constitucionalistas otra, las iusnaturalista otra, las teorías sobre la argumentación jurídica otra, el pragmatismo y el interpretativismo pueden dar respuestas razonables, pero ¿cuál es la más correcta? En este debate está sumergido Dworkin:

"En la práctica uno no puede pensar en la respuesta correcta a cuestiones de derecho a menos que haya reflexionado seriamente, o esté dispuesto a hacerlo, acerca de un amplio y elaborado sistema de principios complejos sobre la naturaleza del derecho....la decisión judicial es un acontecimiento

10 Dworkin desde sus primeras críticas a Hart insiste en que una cosa es ser teórico del derecho y otra cosa ser juez y para hablar con propiedad del tema de los jueces, dice Dworkin, será mejor conocer cómo funciona la práctica judicial, algo que Hart hiciera, pero no del modo profesional a como lo hiciera en la academia. Este argumento Dworkin lo extenderá a todos los teóricos del derecho.

11 Son casos donde el juez aplica el modelo silogístico de la norma al caso. Es decir, si hay un hecho de homicidio y una norma que prohíbe el homicidio, la conclusión debe ser aplicar la sanción que señale esa norma al sujeto que cometió el homicidio. Pero si el caso no es tan sencillo, y el juez debe apelar a otras herramientas, ¿cómo de obrar? Es aquí donde los filósofos del derecho intervienen con sus teorías y los jueces a mantenerse firmes con sus normas. político y los jueces, los abogados y cualquiera que piense acerca del derecho debería dirigir su atención al problema práctico inmediato planteado por cualquier acontecimiento político. La única pregunta debe ser: ¿Cómo podemos mejorar las cosas?" (Dworkin, 2007:64)

La decisión judicial es un acontecimiento político como muy bien lo piensa Dworkin, pero eso no quiere decir que las teorías no jueguen un papel importante. Ahora bien, abordar un examen de las teorías como piensa Dworkin, sin eliminar su tesis del juez Hércules ${ }^{12}$, es una mala alternativa, pues las teorías sólo sirven para decidir en casos difíciles y no en casos sencillos y si la respuesta de Dworkin en los casos difíciles es apelar a Hércules, esto sería un mal argumento, puesto que este al ser omnicomprensivo y que todo lo sabe, no necesita de teorías. Sin embargo Dworkin sostiene:

\begin{abstract}
"No existe inconsistencia alguna entre estas dos imágenes la de Hércules pensando de afuera hacia adentro y la del jurista mortal razonando de adentro hacia afuera. Subrayo la compatibilidad de estas dos descripciones por que a muchos de los críticos del enfoque teorizado les gusta señalar que los jueces reales no son Hércules. Con ello no solo quieren decir que los jueces no son criaturas sobrehumanas sino que mis biografías de Hércules están fuera de lugar" (Dworkin, 2007:69)
\end{abstract}

Un ejemplo explica mejor esto. Supóngase que Dworkin quiere desvirtuar que una teoría de la argumentación no es importante en las decisiones judiciales, se supone, por no haber en sus obras una teoría de la argumentación presente para defender la aplicación de los principios en los fallos judiciales, sino un juez Hércules. Pero como no hay tal juez, la única forma de que un juez pueda apelar a los principios que Dworkin sugiere debe ser la de ampararse en una sólida teoría de la argumentación jurídica, de lo contrario, no es posible un fallo razonable, a no ser, que se crea que un Dios-Hércules, todo poderoso sea el que decida, pero eso es un caso de otro mundo, no del nuestro, los jueces tienen la obligación de argumentar

12 La figura del juez Hércules la presenta Dworkin para mostrar que existen respuestas correctas al derecho y que dicho juez siempre sabrá elegir entre qué principio o regla elige, es un juez sabio. Sin embargo, ¿es posible que un juez mortal pueda seguir los parámetros de aquel juez? 
los casos fallados. Dworkin dice al respecto que "Esto es lo que esperaba capturar para el derecho mediante la historia de Hércules. Mi tesis, repito, es que el razonamiento jurídico presupone un enorme campo de justificación, incluyendo principios muy abstractos de moralidad política, y que tendemos a dar por asumida tal estructura del mismo modo que el ingeniero da por asumido la mayor parte de lo que sabe" (Dworkin, 2007:70). Luego anota: "Solo quiero Decir que el derecho esta calado hasta los huesos de teoría, y que los juristas reflexivos entienden esto aunque no se pongan de acuerdo en qué teoría concreta es aquella de la que están calados" (Dworkin, 2007:71)

Sin embargo, aunque Dworkin sostenga que la teoría es importante, no es coherente cuando sigue defendiendo la respuesta correcta, cuando cree que hay un núcleo duro de significado que no se puede eliminar, cuando defiende una tal objetividad en el derecho, mientras que las teorías serias del derecho, lo que hacen es considerar la posibilidad de que el derecho no posee un teoría consistente y correcta, sólo hay alternativas razonables. Ahora bien y volviendo a Rorty, ¿con qué teorías ataca a Rorty cuando este cree que la realidad no es más que un juego de lenguaje? Dice al respecto Dworkin:

\begin{abstract}
"La existencia de montañas no forma parte de la Realidad Realmente Existente; su existencia simplemente se extrae de un juego del lenguaje que llevamos a cabo...pero esta distinción requiere que podamos diferenciar el sentido de las dos proposiciones siguientes, la primera es que las montañas habrían existido incluso aunque los seres humanos nunca lo hubieran hecho. Esta es la afirmación que Rorty dice que es cierta. La segunda es que las montañas forman parte de la Realidad Realmente Existente. Esta es la que dice que es falsa. Pero juro por mi vida que, da igual cuantas mayúsculas se le puedan introducir" (Dworkin, 2007:74)
\end{abstract}

Dworkin no asume con la seriedad del caso el pragmatismo de Rorty. Como se dijo atrás, Rorty pretende que las creencias que tenemos sobre nosotros mismos deben seguir cuestionándose eternamente para mejorar el progreso moral, porque mientras se pretenda alguna estabilidad en las creencias, pasamos al horror del dogmatismo, limitando así, el avance del conocimiento. Esto no quiere decir que el conocimiento sea de ahora en adelante, con Rorty, incertidumbre, solo quiere persuadirnos de que la filosofía es una lucha con nuestras propias creencias; para el caso de jueces y abogados, es una lucha constante por mejorar sus propias sentencias. En este punto se acercan un poco los dos autores. Los abogados y los jueces, dice Dworkin, deben de ensayar diferentes soluciones a los problemas con los que se enfrentan para ver cuáles funcionan, con independencia de cuales vengan recomendadas o apoyadas por alguna gran teoría. Deben concentrarse en los problemas prácticos que tienen delante de sí y preguntarse cuál de las soluciones disponibles conseguiría que las cosas fueran mejor (Dworkin, 2007: 74)

Sin embargo, este acercamiento no es claro, debido a que su concepción de la verdad judicial es ideal y abstracta cuando apela al juez Hércules. A Dworkin le cuesta aceptar que hay teorías jurídicas que son útiles en la práctica judicial. Por esto sostiene:

\begin{abstract}
"Sólo somos abogados, no filósofos. El derecho tiene su propia disciplina, su arte específico. Cuando vas a la facultad de derecho te enseñan lo que es pensar como un jurista, no como un filósofo. Los juristas no intentan decir grandes cuestiones conceptuales de la teoría ética o política. Deciden cuestiones concretas al por menor, una por una, de una forma más limitada y circunscrita. Sus herramientas de argumentación no son aquellas imponentes que se encuentran en los tratados de filosofía, sino los mas caseros y confiables métodos del análisis textual detallado y a analogía" Dworkin, 2007: 78-79)
\end{abstract}

Con esto se puede ir concluyendo que tanto Rorty como Dworkin hacen intentos por desvirtuar teorías dogmáticas y cerradas, pero que este último, aunque mantiene la idea de una teoría judicial, no se sabe qué tipo de verdad o pretensiones de verdad judicial persiga; debería ser una "verdad o teoría" con minúscula, ya que su interés es mostrar el predominio de la práctica judicial sobre las teorías del derecho que se imponen, pero Hércules deja esto muy difuso. Mientras que Rorty tiene pretensiones un poco más peligrosas para el lenguaje jurídico, el de pretender que todo puede ser revisado en la medida que todo es inseguro. Ahora bien, lo que sí es importante dejar claro desde ya, es que las teorías son útiles en el derecho y que las corrientes 
empiristas o realistas que creen que el derecho no necesita teorías están equivocadas, o los que piensan que la realidad no se cambia con teorías, sino con las prácticas, también están equivocados. Estudiamos el derecho porque se permiten las teorías, de lo contrario, sería una disciplina muy tediosa, encerrada sólo en los códigos, además, habría que quemar bibliotecas enteras. Susntein expresa por ejemplo: "Hay casos que ni siquiera se pueden decidir sin llevar a cabo bastante reflexión teórica. Además, algunos casos no se pueden decidir bien sin tal reflexión teórica. Si existe una buena teoría y se puede convencer a los jueces de que tal teoría es buena, entonces no debería ser tabú que estos la aceptaran" (Sunstein, citado por Dworkin, 2007: 85). A estos argumentos responde Dworkin:

\begin{abstract}
"Coincido con mis críticos en que no todos los jueces tienen educación filosófica. Pero si mis argumentos son sólidos, entonces no tenemos otra opción que pedirles que afronten cuestiones que en ocasiones son filosóficas. La alternativa no es evitar la teorización ética sino mantener su uso en la oscuridad, disimulado detrás de todos los conocidos flogistos jurídicos, como el misterioso arte del razonamiento analógico al modo de los juristas" (Dworkin, 2007:87)
\end{abstract}

$Y$ esto no quiere decir que los jueces tengan que ser filósofos, el hecho de que apliquen una buena teoría no los hace filósofos. Se buscan jueces más serios en su disciplina, ya que no podemos decir que los jueces sean malos filósofos como piensa R. Posner (citado por Dworkin, 2007), pues no son ni siquiera filósofos, como para decir que son malos. "Los malos argumentos ofrecidos por Posner bien pueden ser trampas, ya que una de sus principales tesis es que los jueces no son buenos en el razonamiento filosófico, de modo que puede que esté tentado a sus críticos a ayudarle a demostrar esta tesis mostrando que ello es cierto al menos en el caso de un juez (de uno particularmente, inteligente y eminente)" (Dworkin, 2007:90) Lo que queda de toda esta discusión es que ni los jueces son buenos filósofos, ni los filósofos buenos jueces, todo dependerá de que teorías utilizan para defender sus propuestas sobre lo que sea el derecho o la justicia, sin embargo, el debate teórico seguirá presente independiente de si los jueces son o no filósofos. Las discusiones sobre la justicia o la moral seguirán valiéndose de las mejores tesis esgrimidas por los filósofos, pues son ellos quienes en una profunda meditación pueden brindar mejores respuestas a los jueces en sus decisiones apresuradas. $Y$ otra cosa es que las prácticas judiciales puedan seguir dando elementos para corregir las teorías abstractas que los filósofos proponen.

\section{LA DISCUSIÓN SOBRE LA MORAL EN EL PROYECTO DE R. DWORKIN: ¿MORAL POSITIVA O MORAL JUDICIAL?}

Esta discusión la establece Dworkin básicamente con Richard Posner y lo que pretende es saber si hay una teoría moral sólida defendida en el derecho. De entrada Posner rechaza la teoría moral y piensa que los jueces pueden fallar sin ella. Sin embargo, lo que cree Dworkin es que hay diferentes teorías morales que pueden influir en el derecho como la sociología moral, la antropología moral, la psicología moral, la moral en sí misma, que dependiendo de su comprensión pueden hacer parte de una decisión judicial. El papel de la moral va a estar inmerso siempre dentro del derecho, así sea dentro del positivismo jurídico más injusto, pues las normas tienen una justificación moral que puede darse a partir de un debate democrático o a partir de la justificación de un soberano absoluto; pero además por algo muy simple, las normas son hechas por los hombres y no hay hombres amorales ${ }^{13}$.

Pero independiente de todo esto, la moral de la que está hablando Dworkin es aquella que nos permite legitimar mejor el derecho por fuera de los estatutos, ligada a la práctica judicial, esto es lo que busca al criticar a Hart, a Coleman y Waluchow cuando incorporan la moral al derecho. Para Dworkin hay un concepto más amplio del derecho que vincula la moral para fallar mejor aquellos casos donde los jueces no pueden resolverlos con base en la norma, o cuando las personas tienen dilemas morales bastante fuertes ${ }^{14}$ y requieren

13 Ver a B. Williams en Introducción a la ética, donde explica la distinción entre un hombre moral y un hombre amoral, este último sería lo mismo que un psicópata. Es decir, los hombres que conviven dentro de una sociedad ordenada, necesariamente están vinculados a sus intereses y deseos, pero nunca serán hombres libres de cualquier elemento moral. Así, los jueces no están libres de aquellos intereses y deseos, pensar lo contrario, es romántico, es pensar en un gobierno de ángeles.

14 Para ver la discusión con el positivismo inclusivo o incorporacionista es recomendable ver a Rafael Escudero 
de una teoría moral fuerte. Volviendo a Posner, dice Dworkin, éste intenta rechazar la teoría moral, pero al mismo tiempo cae en ella cuando en su tesis fuerte dice que "Ninguna teoría moral puede aportar una base sólida al razonamiento moral. Por supuesto, esta tesis es en sí misma un juicio moral de naturaleza teórica y global, ya que la cuestión de que si algún tipo de argumento moral provee una base sólida para otro es en sí misma una cuestión moral " (Dworkin, 2007:97). Y más adelante

"Si a la hora de decidir los casos difíciles a los jueces no se les exigiera que tomaran decisiones morales entonces no tendrían desde luego que consultar la teoría moral. Pero si se les presentan problemas morales, entonces decirles que deben resolverlos mediante el uso de la historia, la ciencia económica o cualquier otra técnica no moral supondría un error categorial' (Dworkin, 2007:100) y posteriormente manifiesta:

\begin{abstract}
"Esto sólo quiere decir que, también cuando aparece en la aplicación judicial de la constitución, la argumentación moral es intrínsecamente abierta y controvertida. Posner preferiría que se basaran en algoritmos o en ciencia para que, en el sentido especial que él le da el término, estas cuestiones siempre pudieran ser resueltas por consenso. Pero, para bien o para mal, los jueces afrontan cuestiones morales, y los ataques a la teoría moral no pueden transformarlos en cuestiones matemáticas o científicas" (Dworkin, 2007:105)
\end{abstract}

Por lo tanto, uno de los argumentos más fuertes de quienes atacan una teoría moral en el derecho es la tesis, según la cual, la moral no ha evolucionado como Darwin pensó que evolucionaban las

en Los calificativos del positivismo jurídico (2004), donde expresa por ejemplo sobre Coleman, que la moral puede determinar tanto la existencia como el contenido del derecho con base, por ejemplo, en una ley que establezca el criterio material de validez o la coherencia con un principio moral que causa la validez de aquellas normas que requieran de la prueba moral. El positivismo incorporacionista sostiene la existencia y contenido de la norma y cabe perfectamente que se configure dentro de la regla de reconocimiento del sistema una práctica social de jueces que reconoce como válidas las normas con ciertos criterios morales, ajustados a principios que están determinados en la regla. Y según Waluchow la inclusión de la moral no se produce con carácter necesario en todos los sistemas jurídicos, sino tan sólo en aquellos en los que así se haya establecido. La validez de las normas jurídicas puede depender de la moral, pero no necesariamente. especies. Sin embargo, desde Dewey y Rorty, se cree que las especies son cada vez mejores y, así también, las personas se van comportando con base en las exigencias de la sociedad, las relaciones sociales, familiares a través de un progreso moral. Rorty defiende esta idea en su obra El pragmatismo: una versión (Rorty, 2000), donde defiende la idea de una "justicia como lealtad más amplia" y sostiene que tenemos una "obligación" moral con lo demás. "Supongamos que estamos convencidos de que a través de la evolución los seres humanos desarrollamos actitudes y disposiciones que nos ayudaron no sólo a sobrevivir, sino también a florecer...no tendríamos que decir que sabemos lo que es mejor para nosotros y para nuestras comunidades, sino que sólo tendríamos que tener fe en el proceso que ha hecho que ciertas inclinaciones, actitudes, simpatías y disposiciones sean naturales en distintas comunidades" (Dworkin, 2007:109)

¿Cómo entender, entonces, esta teoría moral en el ámbito judicial? ¿Cómo entender que los jueces cada vez se comportan mejor en aras de una lealtad más amplia cambiando sus precedentes? ¿Será esta su función judicial? La teoría moral de Dworkin basada en una novela de la justicia, donde cada juez sabe lo que debe hacer en cada capítulo, puede ser un fracaso, sino se someten más bien a reglas claras. Para los jueces es mejor hablarles de responsabilidad jurídica que de responsabilidad moral. La responsabilidad moral les exige una tarea enorme que muchas veces ni ellos mismos saben lo que tienen que hacer, mientras que con normas jurídicas sólo deben someterse al imperio de la ley. Sin embargo la tarea judicial no es así de simple. Como diría Isaiah Berlin, siempre nos toparemos con casos donde la colisión de valores no puede sacarse con un respuesta correcta como lo pretende Dworkin, esto sólo se podría lograr en un mundo perfecto donde todo está en armonía, como diría el mismo Rousseau, un mundo que no es propio de los hombres, si no de ángeles. El problema es que en el derecho hay muchos casos donde el juez debe decidir teniendo en cuenta cuestiones morales y políticas, y en estos casos pueden sacrificarse valores invaluables para una sociedad: "Lo que resulta claro es que los valores pueden colisionar. Los valores pueden fácilmente estar en conflicto dentro del seno de un mismo individuo y de ahí no se sigue que algunos deban ser verdaderos 
y otros falsos... algunos de los bienes más grandes no pueden vivir juntos. Esta es una verdad conceptual. Estamos condenados a elegir, y cada elección puede comportar una pérdida irreparable" (Dworkin, 2007:123) En consecuencia, en un mundo tan contradictorio como el que se tiene, siempre habrá un peligro de perder el derecho para alguien:

"Por supuesto, una comunidad política no puede alcanzar todo el éxito económico o cultural que sus ciudadanos sueñan, y es claro que sus políticas tendrán a veces que decepcionar algunos ciudadanos a través de medidas que benefician a otros... si aceptamos la libertad como valor y pensamos que esta se vulnera cuando se exige a los ricos pagar impuestos para reunir más dinero para los pobres, entonces pensaremos que estos impuestos no sólo incomodan a los ricos, sino que supone una injusticia hacia ellos" (Dworkin, 2007:127) Por consiguiente, una teoría moral adecuada dependerá de qué entiendan los jueces por los valores y cómo los aplican en las prácticas judiciales para resolver el conflicto entre ellos. Será esto acaso un anuncio de Dworkin para que los jueces hagan un esfuerzo por parecerse a Hércules, o lo que es lo mismo, ¿ser jueces filósofos? Pues estos debates morales son propios de temas académicos de alto nivel y "Dependerá de que entendamos por libertad e igualdad: de cómo concibamos estos valores abstractos...la libertad afirma Berlin es libertad frente a la interferencia de los otros en los actos que podrías llegar a hacer, sean los que sean. Por su puesto, si es así como comprendemos la libertad, resultará sin duda evidente que la libertad para el lobo, como este autor afirma es la muerte para el cordero" (Dworkin, 2007:129)

Pero con estas definiciones de igualdad o de libertad siempre se cometerá un daño. Por esto al decir de Dworkin, la libertad no es la libertad para llevar a cabo aquello que podrías querer hacer; es libertad para hacer lo que desees en la medida en que respetes los derechos morales de otros correctamente entendidos. Sin embargo, la salida de Dworkin frente a la propuesta de Berlin es que las definiciones de valores no pueden ser dogmáticas, porque de esa manera habría un choque entre los valores y por supuesto habría que escoger un valor por encima de otro. Es decir, para Dworkin no hay conflicto de valores, porque existe una elección racional de los jueces, ¿de dónde saca esto? De su experimento mental con el juez Hércules.

De modo que, sería más razonable pensar en términos de Robert Alexy cuando cree que los valores no deben chocar, sino más bien que colisionan, así, la elección de un valor no perjudica a los otros, ambos principios o valores sobreviven dentro de la regla de ponderación ${ }^{15}$, pues no es un choque entre reglas donde alguna debe ser sacrificada. Esta sería la forma de defender un pluralismo de valores dentro de una comunidad jurídica en conflicto. En definitiva, Dworkin no alcanza a salvar la teoría de las reglas y principios, basado en una moral de Hércules, si al lado de ella no existe una teoría de la argumentación jurídica que la respalde, es decir, los jueces sólo pueden ponderar valores o principios si se adaptan, en general, a los postulados de la argumentación jurídica, y en especial, a las tesis de R. Alexy, desechando cualquier síntoma de un juez omnicomprensivo y absoluto. Por lo tanto, Dworkin no ofrece ni en las anteriores obras de los setenta y ochenta, ni en La justicia con toga un método para que el juez en los casos difíciles pueda resolver de manera correcta. Dworkin sólo atina a criticar las tesis de la interpretación y del originalismo, sin dar una respuesta convincente sobre por qué se debe abandonar a Hart en su versión del Postscriptum, donde asume una posición moderada del positivismo al incluir los principios del derecho, para que el juez a través de su regla de reconocimiento y las fuentes sociales del derecho motive sus fallos, y para que en casos de vaguedad jurídica apelen a los principios plasmados dentro de una moral positiva.

En fin, sólo la moral positiva, no la moral judicial o subjetiva de los jueces, podrá ser la motivante de sus fallos judiciales. Ni los principios abstractos, ni la moral de Hércules servirán para salvar la teoría moral de Dworkin, los jueces tratan con casos concretos y con sus limitantes cada vez más abrumadoras de los casos reales, recordándoles

15 La regla de la ponderación aunque fue propuesta por Robert Alexy es muy común que se utilice en la lógica retórica, como aquella que permite elegir valores en conflicto sin que se sacrifiquen los demás. Por ejemplo, cuando una persona tiene que elegir entre estudiar o trabajar, tendrá que decir qué es lo más razonable para su vida actual y futura. Sobre estos mismos debates se encuentran los jueces cuando van a conceder derechos. 
que cada vez se alejan más de un juez virtuoso e ideal, pero más cerca de la realidad jurídica preexistente, desamparados de un teoría judicial empírica acorde con sus necesidades reales. Así las cosas, las propuestas del positivismo hartiano e inclusivo no logran superarse con las críticas de Dworkin, por el contrario, son cada vez más útiles en el ambiente jurídico contemporáneo, pues en general, casi todas, han venido a fundar el estado constitucional donde los jueces son protagonistas desde el punto de vista de la moral positiva. Pero esto no quiere decir, entonces, que Dworkin no haya propuesto algo interesante, lo que sucede, es que tanto el positivismo jurídico en mención como el positivismo principialístico de Dworkin, guardan algo semejante, defender la moral, valores y principios dentro de los sistemas jurídicos basados en reglas. Lo que los hace distintos es su metodología judicial y teórica. Por ello, se ofrece en este último ítem una alternativa razonable de Dworkin frente a este difícil laberinto, su tesis de la interpretación que en Hart y demás estaba casi nula.

\section{FIDELIDAD AL TEXTO, INTERPRETACIÓN Y DEMOCRACIA JUDICIAL: UN PRESUPUES- TO DE LA HERMENÉUTICA JURÍDICA}

En los casos difíciles el juez se ve obligado a interpretar, argumentar y justificar sus decisiones, pues está en riesgo la seguridad jurídica y el precedente judicial, y como diría Perelman (1988) y Robert Alexy, el juez que cambie el precedente está obligado a justificar por qué el suyo es más razonable que el anterior. Dworkin tiene claro este tema, pero sólo intenta mostrar, de modo general, en qué consiste la interpretación constitucional y los peligros de la fidelidad al texto de la constitución.

"Los abogados y jueces que afrontan una cuestión constitucional contemporánea deben de intentar construir una interpretación coherente, ajustada a principio y persuasiva del texto de las concretas cláusulas, la estructura global de la Constitución y nuestra historia bajo esta Constitución. En otras palabras deben de pretender la integridad Constitucional. La fidelidad del texto de la Constitución no agota la interpretación Constitucional, y en algunas ocasiones la integridad Constitucional puede requerir alcanzar una conclusión que no pueda justificarse o incluso contradiga la mejor interpretación del texto constitucional" (Dworkin, 2007:136) Y más adelante: "Algunos académicos dirán que deberíamos intentar descubrir no aquello que pretendían quienes escribieron o rectificaron la Constitución y sus diversas enmiendas, sino lo que preveían o esperaban que se desprendiera del hecho de decidir lo que dijeron, lo cual es una cuestión muy distinta. Otros dirán que debemos ignorar el texto mismo a favor de aquello que la mayoría de las personas durante la mayor parte de muestra historia pensaron que significaba"

(Dworkin, 2007: 137)

Estas minucias de la interpretación nos conducen a buscar cuál es el límite de la interpretación, si hay un campo semántico hasta donde los jueces deben llegar. ¿Es la Constitución el límite?, ¿la costumbre?, ¿el precedente?, ¿la ley? ¿Qué es? Ya en Gadamer en Verdad y Método II (1977) había dicho que la hermenéutica va hasta el texto mismo, pero dicho texto no es un objeto de la física que se pueda manipular fácilmente. Por eso cree que cuando se busca el sentido de los textos se logra por una "pre-interpretación" que me ofrece el texto donde el hablante no tiene porque introducir elementos nuevos. El otro paso es la "interpretación", donde ya el hablante entra a dialogar con el texto, trata de entender lo que el texto le quiere decir, pero siempre apuntando hacia el corazón del texto, hacia la naturaleza del texto. Finalmente esta la "aplicación" del texto que es la utilidad que le va a dar el intérprete al texto, su adecuación con la realidad.

Es claro que la interpretación jurídica en muchos casos es un diálogo con los muertos ${ }^{16}$ y en estos casos se hace más difícil la interpretación, pero como diría Dworkin, no se trata de buscar que había en los cerebros de los muertos. "Se trata de un ejercicio de lo que he denominado interpretación constructiva. No significa que se tenga que fisgonear en los cráneos de personas que llevan siglos muertas, sino que hay que intentar encontrar el mejor sentido a un evento histórico " (Dworkin, 2007:138)

De esta manera la práctica constitucional va a consistir en "Cualquier estrategia de argumentación Constitucional que pretenda la integridad Constitucional global, tiene que buscar respues-

16 Es decir, muchos de los constituyentes que crearon la Constitución ya no existen para preguntarles que querían decir en determinas normas, así que al intérprete le toca devanarse la cabeza con el texto literal. 
tas que se compaginen suficientemente con nuestras prácticas y tradiciones (que encuentren suficiente apoyo tanto en nuestra historia como en el texto de nuestra Constitución) de modo que pueda considerarse que tales respuestas describen nuestros compromisos como nación" (Dworkin, 2007:140)

Por consiguiente, la discusión con Scalia ${ }^{17}$ sobre el originalismo semántico y el originalismo de la expectativa nos va a llevar a un terreno más claro sobre la interpretación. Miremos primero en qué consiste. "El originalismo semántico, que entiende que lo que colectivamente querían decir los legisladores es decisivo para la determinación del significado Constitucional, y el de la expectativa, para el que lo decisivo es qué esperaban conseguir al decir lo que dijeron " (Dworkin, 2007:143)

Posteriormente Tribe $^{18}$ ataca a Dworkin sobre la posibilidad de encontrar datos empíricos en la interpretación, o lo que es lo mismo, llegar hasta una realidad de los hechos pasados. Al decir de Tribe: "No estoy de acuerdo ni con el profesor Dworkin ni con el juez Scalia en que uno pueda descubrir.... Datos empíricos sobre lo que quería decir un determinado grupo de personas en momentos concretos de nuestro pasado" (Tribe, citado por Dworkin: 143) Pero Dworkin vuelve a responder que la interpretación no es como las matemáticas ni son fisgoneos intracraneales.

"La interpretación constitucional no es como las matemáticas y sólo un tonto pensaría que sus juicios Constitucionales están más allá de cualquier objeción concebible...como expuse antes, la gente traduce lo que la otra gente dice- le separe una mesa o varios siglos- mediante un proceso de interpretación constructiva que no pretende fisgoneos intracraneales sino ofrecer la mejor explicación posible de su discurso. Es un proceso normativo, no empírico" (Dworkin, 2007:145)

17 Scalia fue un juez que defendió radicalmente la interpretación originalista de las normas, es decir, los jueces no pueden interpretar más allá de lo que las normas significan o dicen.

18 Autor, que como el anterior, cree que la interpretación judicial sólo puede encontrarse en las palabras escritas de la ley, no en otra parte, por ejemplo en la intencionalidad del legislador, eso sería pasar a una interpretación metafísica de adivinar qué quiso decir un muerto.

Tribe parte de que la Constitución es el único parámetro para interpretar, así defiende la fidelidad al texto constitucional. Sin embargo, Dworkin cree que hay formas de salir al paso a la fidelidad del texto de la Constitución. Por ejemplo, "Cuando no haya manera de reconciliar el texto y la práctica a lo largo del tiempo pueden en principio desbancar incluso a una pieza tan básica de los elementos interpretativos como el texto de la Constitución" (Dworkin, 2007:147) Dworkin da tres maneras de no ser tan fieles a la Constitución. La primera es la justicia.

\begin{abstract}
"En algunas circunstancias la justicia podría pasar por encima de la fidelidad...como la Constitución contiene principios morales abstractos, la fidelidad les da a los jueces demasiada manga ancha para censurar las leyes que les parecen injustas, aunque estas hayan sido aprobadas por un parlamento adecuadamente elegido" (Dworkin, 2007:150)
\end{abstract}

\subsection{La segunda es la democracia.}

"Si nos preocupa nuestra democracia tenemos que hacer oídos sordos a la fidelidad, al menos en el caso de las grandes cláusulas abstractas de la Constitución, e insistir en un papel más modesto para nuestros tribunales...definimos la democracia de otra forma, entendiendo que significa autogobierno de todos actuando conjuntamente como miembros de igual estatus de una empresa conjunta cooperativa...no puede haber democracia concebida como una empresa conjunta de autogobierno a menos que todos los ciudadanos tengan la oportunidad de desempeñar un igual papel en la vida política, lo que no sólo significa un igual derecho de voto sino una igual voz en las deliberaciones públicas formales y en los intercambios morales informales" (Dworkin, 2007:151)

\subsection{Finalmente el pragmatismo.}

"Durante décadas el pragmatismo ha tenido una cierta influencia en la teoría jurídica estadounidense, y ahora está experimentando una suerte de renacimiento, especialmente en la teoría Constitucional. El pragmatismo jurídico sostiene que las decisiones judiciales deberían ser limitadas cautelosas y experimentales. Según los pragmatistas los jueces deberían concentrarse en las circunstancias concretas ilimitadas y limitadas de los casos en litigio e intentar exclusivamente encontrar soluciones 
para los asuntos e intereses que resulten exitosas en ese limitado marco" (Dworkin, 2007:153) Para llegar a la conclusión: "La democracia no es sólo la regla de la mayoría sino una asociación en el autogobierno....tal asociación es hecha posible por una Constitución moral... Los jueces aplicarán esas garantías de igualdad ciudadana" (Dworkin, 2007:157)

Con estas apreciaciones Dworkin quiere seguir defendiendo la "novela de la justicia" donde cada juez tiene que tener muy claro su función. Tendrá que tener presente los fallos de los demás jueces para no desviarse de la justicia que están construyendo entre todos. Tendrán que ser obedientes a la ley y a la Constitución, pero si en algunos casos pueden apartarse de lo que dice literalmente el texto, lo podrán hacer apelando a la justicia, a la democracia asociativa y a un derecho integral e interpretativo que no se convierta en arbitrariedad. Sin embargo, el error de Dworkin es no establecer un método judicial de cómo deben obrar los jueces y sus sugerencias en contra de las teorías filosóficas o morales que más han aportado a las disciplinas, sólo ha ofrecido intuiciones filosóficas débiles, apelando a la experiencia judicial que lo hace fuerte como juez de los Estados Unidos. De ahí que debamos terminar con una idea corta, pero contundente de Alexander Bickel, (Bickel, 1962):

Los jueces tienen una deferencia con el legislador, pero en casos donde el legislador no medite bien sus leyes y se promulguen sin ninguna preparación seria, los jueces podrán intervenir a través del uso de la revisión judicial o el control judicial de leyes para declarar inconstitucional lo que no es conforme con la Constitución. Para ello los jueces apelarán a sus "virtudes pasivas" que son principios del derecho que funcionan como directrices judiciales para casos donde el legislador no realizó bien su tarea. Tendrán que apelar a teorías jurídicas y constitucionales que mejor respalden sus razones. Esta propuesta es la que hoy en día predomina en la Corte Constitucional colombiana, esto es, los legisladores no dicen todo lo que sea el derecho o la justicia, también los jueces tienen un lugar estratégico para decir en sus fallos qué justicia, qué derecho y qué democracia queremos.

\section{CONCLUSIONES}

Dworkin, después de este debate que emprende frente a una multitud de argumentos en su contra, no sale muy bien librado. A pesar de su autoridad para hablar sobre estos temas, sus argumentos no son suficientes para cerrar de plano estos debates como él lo pretende. Por ejemplo, para el caso de la respuesta correcta se encuentra con los poderosos argumentos de Isaiah Berlin cuando le expone en los Dos conceptos de libertad que los valores van a entrar en conflicto y, por consiguiente, siempre va haber un sacrificio de un principio o un valor cuando en una decisión choquen o colisionen dos de ellos, como es el caso de la libertad con la igualdad. No cree que la respuesta de Dworkin de que el juez Hércules lo pueda resolver todo pueda ser útil, pues aquí se trata es con jueces mortales y no con jueces de Estados ideales que son paraísos utópicos que no existen.

Otro error en el que permanece Dworkin es que insiste en decir que ya dio respuesta a las tesis de Hart y que el tema está superado, pero no es convincente con sus afirmaciones, porque sigue sosteniendo un concepto criteriológico del derecho en Hart, algo que el propio Hart no defiende, pues su regla de reconocimiento guarda un grado de incertidumbre que no dice todo el derecho, produciendo en los jueces la interpretación, la discrecionalidad fundada a través de los principios que el propio Hart señala en el Postscriptum.

Otro argumento ad homine frente a Hart y ya lo había mencionado Dworkin en el Imperio de la justicia (Dworkin, 2005) y en los Derechos en serio (Dworkin, 1984), es que piensa que Hart por ser solamente un académico no puede hablar de la práctica judicial, porque no tiene la experiencia judicial. Con base en esto se debe decir también que lo mismo habría que decir de él, pues al no ser exclusivamente un filósofo o un académico y que sólo está dedicado a la práctica judicial no puede enfrentar a Hart en sus teorías. Pero independiente de esto, es un debate que no tiene sentido, ya que tanto la práctica como la teoría se requieren en los debates académicos, y no como argumenta Dworkin:

"En la actualidad se entiende de modo general que la versión del positivismo doctrinal de Hart, que ha sido influyente en la filosofía del derecho 
académica estadounidense pero no en la práctica jurídica, no es un ejemplo de positivismo jurídico, sino de positivismo analítico...... sin embargo, en la actualidad la versión más notable del positivismo político es una teoría sobre cómo debe de interpretarse la constitución de los estados unidos, teoría que tiene una enorme importancia practica" (Dworkin, 2007:34) Esto sería desconocer el aporte que ha realizado Hart a los sistemas jurídicos ${ }^{19}$.

\section{Y continúa diciendo,}

"En primer lugar, los cursos denominados "teoría del derecho" ya no se dedican sólo o si quiera principalmente a tales cuestiones conceptuales sino que se ocupan de una gran variedad de temas más políticos acerca, por ejemplo, del papel de la ciencia económica en el derecho, la sociología del derecho, el feminismo y lo que de modo revelador se llama teoría racial critica" (Dworkin, 2007:44) Dworkin tiene un propósito con Hart, atacarlo y eliminar del todo su propuesta del Concepto de derecho de 1961, su error es hacerlo sólo desde la práctica judicial y desprestigiando cualquier teoría jurídica conceptual. La gran conclusión que se extrae de la obra La justica con toga, es que los jueces, a pesar de que no son filósofos por profesión, si deben parecerlo en la práctica judicial, pero sus temores por el prevaricato judicial los han llevado a alejarse demasiado de aquel ideal filosófico, volviéndose cada vez más, simplemente operadores jurídicos. O como dijera alguna vez un juez, "sólo somos intérpretes moderados, no filósofos". Pero los jueces deben aspirar a algo más valioso, ser promotores de la democracia y para ello no pueden seguir siendo, entre los poderes públicos, el poder más débil, por el contrario, deben representar el poder más robusto para no sacrificar los valores fundamentales dentro de una democracia ilegítima, para ello tendrán que ser más experimentados en las teorías filosóficas y jurídicas, y desobedecer al juez Holmes en su sentencia inicial: los jueces si están para hacer justicia.

19 En Colombia, por ejemplo, son muchas las sentencias de jueces que citan al profesor de Oxford para motivar sus fallos.

\section{REFERENCIAS BIBLIOGRÁFICAS}

ALEXY, Robert. (2007). Teoría de los derechos fundamentales. Traducción de Carlos Bernal Pulido. Madrid: Centro de estudios políticos y constitucionales.

ALEXY. Robert. (2007). Teoría de la argumentación jurídica. Traducción de Manuel Atienza e Isabel espejo. Madrid: Centro de estudios políticos y constitucionales.

AUSTIN, John Langshaw. (1990). ¿Cómo hacer cosas con palabras? Barcelona: Editorial paidós.

AUSTIN, John. (2002). El objeto de la jurisprudencia. Traducción de Juan ramón de Páramo. Madrid: Centro de estudios políticos y constitucionales.

BICKEL Alexander. (1962). The Least Dangerous Branch: The Supreme Court at the bar of politics. Yale University Press, New Haven.

DWORKIN R. (2007). La democracia Posible. (Principios para un nuevo debate político). Traducción de Ernest Weikert García. Barcelona: ediciones Paidós.

DWORKIN Ronald. (1984). Los Derechos en serio. Traducción de Marta Guastavino. Barcelona: Editorial Ariel.

DWORKIN, Ronald. (2002). Cómo el derecho se parece a la literatura. En: La decisión Judicial. El debate Hart- Dworkin. Bogotá: Siglo de hombres editores, universidad de los Andes

DWORKIN, Ronald. (2005). Imperio de la justicia. Traducción de Claudia Ferrari. Barcelona: Editorial Gedisa

DWORKIN, Ronald. (2007). La justicia con toga. Traducción de Marisa Iglesias Vila e Íñigo Ortiz de Urbina Gimeno. Madrid: Marcial Pons.

ESCUDERO, Rafael. (2004). Los calificativos del positivismo jurídico. Madrid: Ediciones Civitas.

GADAMER, G. (1977). Verdad y Método II. Traducción de Ana Agud Aparicio y Rafael de Agapito. Salamanca: Ediciones sígueme.

HART, Herbert. (2004). Concepto de derecho. Traducción de Genaro Carrió. Buenos Aires: Abeledo-Perrot.

HART, Herbert. Postscriptum. (2002). Traducción de Magdalena Holguín. En: La decisión Judicial. El debate Hart- Dworkin. Bogotá: Siglo de hombres editores, universidad de los Andes HECK, Philipp. (1932) Jurisprudencia de intereses.

KELSEN, Hans. (2006). Teoría pura del derecho. Traducción de Moisés Nilve. Buenos Aires: Eudeba.

MOORE. G. Principia Ethica. Colección filosofía contemporánea. UNAM

PERELMAN, Chaïm. (1988). La lógica jurídica y la nueva retórica. Traducción de Luis Diez-Picazo. Madrid: Editorial Civitas.

PLATÓN. (2003). Diálogos. México: Editorial Porrúa. 
RORTY, Richard. (2000). El pragmatismo, una versión. Traducción de Joan Vergés Gifra. Barcelona: Editorial Ariel.

RUSSELL, Bertrand. (1972). Fundamentos de filosofía. Traducción de R. Crespo y Crespo. Barcelona: El Arca de papel.

SEARLE. John. (1995). La construcción de la realidad social. Traducción de Antoni Doménech. Barcelona: Editorial Paidós.

SUNSTEIN Cass, (1996). Legal Reasoning and Political Conflict, Nueva York: Oxford University press.

WILLIAMS Bernard. (1998) Introducción a la ética. Traducción de Manuel Jiménez Redondo. Madrid: Ediciones Cátedra.

WITTGENSTEIN. (2005). Tractatus lógico-philosophicus. Madrid: Alianza editorial. 